Askins, K. (2018) Feminist geographies and participatory action research: Co-producing narratives with people and place. Gender, Place and Culture, 25(9), pp. 1277-1294.

(doi:10.1080/0966369X.2018.1503159)

There may be differences between this version and the published version. You are advised to consult the publisher's version if you wish to cite from it.

http://eprints.gla.ac.uk/165877/

Deposited on: 28 August 2018

Enlighten - Research publications by members of the University of Glasgow http://eprints.gla.ac.uk 
Feminist Geographies and Participatory Action Research: Co-producing Narratives with People and Place

Kye Askins*

School of Geographical and Earth Sciences

University of Glasgow

Room 517, East Quadrangle

Glasgow G12 8QQ

Tel: +44(0)141330 2289

Kye.Askins@glasgow.ac.uk

Ackn: N

CN: Y

Word count: 7019 


\title{
Feminist Geographies and Participatory Action Research: Co-producing Narratives with People and Place
}

\begin{abstract}
This review offers thoughts, queries and hesitations regarding articles drawing on participatory action research (PAR) published over 25 years of Gender, Place and Culture. It foregrounds the interconnections and overlaps between PAR and feminist geographies, and considers a continuum of participations-collaborations-actionsknowledges co-produced across a range of interrelated feminist methodologies. I emphasise epistemological commitment as central to PAR, pointing to work in GPC that evidences critical approaches to research process, embedded in feminist perspectives regarding how scholars re-produce the world and/as act/ing in the world, particularly in attending to shifting, situated and complex subjectivities and power inequalities. Working together with participants is vital, through an ethic that centres participants' voices, as actors in their own lives. Highlighting the emotional and embodied geographies that weave through such research and writing, this review suggests deepening and strengthening interdependences and a feminist ethos of care as researchers, to further foreground diverse stories and voices, work towards social and spatial justice, and co-produce progressive changes with people and place.
\end{abstract}

Keywords: action; collaborative research; emotions; feminist methodology; participatory action research

\section{Inspirations}

Once upon a time there was a PhD student. In her 30s, with two small children and a background in the voluntary sector, she came to a human geography department hoping that research would enable more effective intervention around issues of injustice than was her experience as a project worker.

Having never studied any kind of social science, she was encouraged to join Masters' level taught courses in the department, which were equally fascinating and frustrating to her. At a time when actor network theory was being wrung through a spatial lens, emphasis was 
firmly on the poststructural, and non-(more-than) representational theory. Deleuze, Guattari and similar writing/thinking was all-pervasive, opening up new horizons to her, yet landscapes in which it was difficult to find purchase for her previous experience.

A few months into the $\mathrm{PhD}$, she was struggling to 'make sense' ... of the relevance, the politics of most 'set readings', but more widely of what she was doing in the academy. Then one day, Kay Anderson, giving a Masters seminar, suggested she read articles in Gender, Place and Culture (GPC); work that might resonate more for her.

At that time, hard copies were the norm, so she went into the library and found the journal on a shelf, picked up almost half the available issues (the first three years) and took them to a quiet corner. The worlds presented in those pages were as complex, contested, unruly, shifting and provoking as those in the 'set readings', and often drew also on poststructural perspectives - yet were evidenced through rich, grounded empirical material full of voices, people and lives, including those of researchers. And written with politicised intention, to highlight and challenge gender/other inequalities. She felt 'home', recognising the language, terms, characters, disagreements and diverse positions. She felt involved with these texts, rather than being spoken at.

That afternoon, one article held her attention in particular. "'Stuffed if I know!": Reflections on post-modern feminist social research' by someone called J.K. Gibson-Graham (1994), who wrote how they resisted any assumption that they were a knowing subject, while having situated knowledge of value:

At times I have felt at a loss to know why I was researching mining town women at all and whether what I was doing was in any way feminist research. And yet, like Leanne, I do know something and I could try to communicate my own emerging ideas about doing anti-essentialist post-modern feminist social research and negotiating the difficult questions of subjectivity and identity. (ibid., 206)

'Telling the tale' of research shaped through feminist debates, Gibson-Graham clearly 
involved women as active participants, in processes through which they challenged normative negative representations, and their voices and agency were centre: attempting 'direct intervention in power relations' in a process of 'action and participatory research' (215), with mining town women as co-researchers.

Reading this, she began to see what she might do in the academy, and has been trying to follow related paths ever since.

\section{Aspirations}

Indeed, 'Stuffed if I know' and other GPC articles were influential in helping me come to understand theory and practice as implicitly political, 'knowledge and its production as an always already political process' (ibid., 214). Feminist scholarship more widely has enriched my understanding of theory as practice, with ideas and writing as intervention, and practice as theory, with actions mutually co-constructing concepts. Such interwovenness is become enmeshed in how I attempt to undertake participatory action research (PAR). Critically, this theory-praxis nexus is central to PAR as an epistemological commitment, and ontological orientation, requiring constant (re)appraisal of how, as an academic/researcher, I can understand the world, and simultaneously be in the world.

Yet/and I don't wish to over-define PAR here, since my experiences and reading for this piece reiterate the pluralities, fluidities and challenges inherent in such commitments and orientations. PAR is more-than-method; participation-action-research can't easily/necessarily be bounded, rather my aspiration is to tease out how it is tethered to embodying feminist principles: contemporary 'participatory research' as an evolving set of diverse feminist approaches (Marston and Doshi, 2016). As such, PAR is framed as an ethic of social justice: what PAR involves and how it speaks to feminist geographies is intended to unfold through this narrative. 
Through GPC, I've also learned the importance of stories: the politics of witnessing and telling, as central to unpacking subjectivities, rendering visible social and spatial power relations, in co/making knowledges. Unsettling the masculinist, colonial 'eye' of objective knowing. Thus I aim here to remain transparent regarding issues of voice. Invited as an individual to write a 'review' of PAR articles in GPC, this is a multi-authored piece, in that its thoughts come through many years learning through PAR with a diverse range of participants. Collaborative writing remains difficult within normalized academic publishing structures (a point I return to later), and meaningful collaboration was unfeasible for this particular narrative. I deploy 'et al.' to indicate the co-authorship inherent, mindful of the multiplicity of voices who I have a responsibility to/yet can never 'represent' (after Cook et al. 2014). I simultaneously acknowledge my privileged position in the (western) academy, and admit gaps, omissions and misunderstandings as my own. In this, I follow Richa Nagar (in Chowdhury et al. 2016, 1810):

\footnotetext{
If we see "feminisms" as plural articulations beginning with small "f"s, they cease to be a coherent ideology or school of thought that can materialize only through an abiding commitment to disciplinary procedures and exercises of hegemonic power. [...] feminisms can offer a richly chaotic terrain for undoing all cannons and for enabling an ever-contested, embodied, tentative, and unfolding cocreation with differentially situated knowledges and experience.
}

I offer, then, thoughts, queries and hesitations as re-view of PAR, to try to speak to the interconnections with feminist geographies: the continuum of participations-actionsknowledges-pedagogies-policy interventions and so on. Louise Johnson (2008, 562), reflecting on 15 years of GPC, argues that its articles offer key 'interrelated sites of engaging but also transformative activity: empirical, theoretical and political', in which I read a critical approach to participation as vital. 
As all written work, this re-view is navigated through an (artificial) structuring of sections, to corral into narrative these interrelated sites. It begins by considering work in GPC explicitly self-identifying as PAR, to highlight the multiplicity of concerns grounded in empirical work committed to social justice. It then explores articles in GPC that speak similarly to feminist principles through collaborative working, foregrounding the critical challenges around whose voices remain in/excluded in feminist productions of knowledges, and the porous boundaries around what might be counted/considered as PAR. I next move to emphasise 'action' as that aspect which most sets PAR aside from other feminist research: action together with people in participatory process, as central to an ethic of progressive change. The review considers challenges with/in PAR throughout, and also in the following section, to highlight the persistent work demanded in negotiating differently positioned participants, researchers and voices, as central in co/producing worlds. I end by considering the emotional and embodied dimensions and geographies of such working, and calling for increased emphasis on interdependence and care ethics in how and what we do-and-write, think-and-feel, to further foreground diverse voices and work towards justice.

\section{Participations}

There are ten articles that use some combination of participatory/action/research as a 'keyword'. Astonishingly rich, diverse and thought-provoking, these articles highlight key issues and challenges called forth and out in PAR, and foreground the contested, plural and dynamic qualities of critical participation.

Caitlin Cahill $(2007,267)$ emphasises the multiple, complex and difficult ways in which new subjectivities evolve for participants and researchers, understanding/experiencing PAR as poststructural becomings through which 'personal (and social) transformation' may be possible. Issues of power, scale and the politics of location are central to working with 
young urban women of color, in a project through which they come to educate themselves and others about how they are structurally marginalised, through critical pedagogy that aims to challenge such restrictions and transform their worlds (after Freire 1997): 'through a process of investigating their own everyday lives and collective reflection, research participants identify their individual experiences as shared, as social, and then in turn as political' (268).

Kath Browne and Jason Lim (2010) similarly refuse hopelessness, or re-iterating participants (people identifying as trans-) as only excluded or marginalised. Working through a community-university partnership to transcend boundaries 'between health, politics and uses of city spaces', Browne and Lim's project explores and enables the building of solidarities among/across trans-individuals, as simultaneously created and contested (615). Also working with issues of trans/gender, Alison Rooke (2010) offers analysis through a participatory arts project, which itself produces transgendered spaces through 'the logics of recognition, creativity and pedagogy' (655). Both articles foreground identities as fluid and intersectional, embodied and political, working with participants to explore how everyday sites are relational with broader structures of discrimination, and searching for ways to shift discursive and material exclusions.

Louise Waite and Cath Conn $(2011,115)$ discuss the ethical issues caught up in 'feminist 'ways of knowing' and epistemologies, in order to discern gender-based disadvantage $[\ldots]$ from the standpoint of women'. Working through participatory video drama with young women in Uganda, they argue that 'doing research differently', PAR is an ethical and rigorous response to specific research questions/project/sites; that PAR is not without power inequalities, rather it is 'far more productive to explore the nuanced issues of the spatialities of power, multiple knowledges and representations within participatory approaches' (116). Katherine Brickell (2015) builds on Waite and Conn's work with video 
drama to create and explore stories co-produced with participants in Vietnam, drawing on their capacity to analyse and transform their lives. Critical pedagogies is again central, through reflexive process and 'looking alongside' rather than 'looking at' research subjects' (Kindon 2003, cited in Brickell 2015, 512). As Brickell compellingly shows, performances in/for video can, through relational geographies, then be 'performed' in everyday lives, to enact transformative social relations.

Katarina Giritli-Nygren and Ulrika Schmauch (2012) thread themselves through research and text as co-researchers with migrant women, co-producing thick descriptions and a cacophony of voices that tell of vibrant, marginalised yet mutinous spaces of dis/connection in Sweden. Grounding research through participants' suggesting, taking and discussing photographs of their everyday lives, ideas and action are brought forth through women's perspectives, which refuse any collapse into easy integration-segregation or in-exclusion binaries. Such nuance and complexity is also evident in Lindsey Carte and Rebecca Torres' (2014) work, which utilises role-playing to build a geopolitical analysis, in which a PAR of multiple methods uncovers geographies of state power as experienced in women's lives on the Mexico-Guatemala border. As in articles above and below, the need to build trust and develop relationships alert to difficult negotiations of power and subjectivities is evident, the authors creatively engaging with Central American immigrant women and enacting a 'feminist ethics of care'.

Discussing the ways in which mothers 'talk back' to denounce injustice, by producing new knowledges and confronting social service practitioners, Isabel Berckmans, Marcela Losantos Velasco and Gerrit Loots (2016) also attend to the personal and social transformational potential of PAR. Understanding research as a journey together with mothers of street children in Bolivia, sharing stories is described here as an opening towards trust, in which listening is crucial as a relational, people-centred feminist methodology. This 
paper evidences how new subjectivities, and 'action' through meetings with and a newsletter for local social service practitioners, can be powerful re-positionings, albeit partial and fragile.

A similarly critical tone is evident through Kath Browne, Niharika Banerjea, Nick McGlynn, Sumita B., Leela Bakshi, Rukmini Banerjee and Rannjita Biswas’ $(2017,1)$ conversations around transnational feminist queer methodologies. Through making research team debates transparent, they emphasise 'the transnational as a methodology composed of a series of flows'. On projects that involve academics and/as activists in dissimilar places distant from each other, as well as diverse participants, there is compelling imperative to comprehend and work with the disparate effects of 'scattered colonialisms, neoliberalisms and homonationalisms' (3). In a multi-spaced (including virtual) endeavour, these authors honestly call up and out the difficulties and power relations involved when reaching for dynamic networks through intercultural exchanges.

Before the introduction of keywords, Alice McIntyre (2003) explores the use of photovoice and PAR in re-imagining place and identity in a working class community in Belfast, through which women place themselves in everyday contexts. McIntyre conceptualises PAR as emphasising 'social change as an integral aspect of social science research' (48), and in the photo-text exhibition that evolved, displayed at the West Belfast Festival, images of 'special places' jostled amid spaces of fear and oppression, with neither 'public' nor 'private' settling into either category. While in 2004, Cathy McIlwaine and Kavita Datta argued the need for more holistic approaches to sexuality, youth and gender to address HIV/AIDS epidemic in Botswana. They used 'participatory urban appraisal', aware of its limitations and critique, to try to avoid 'reactionary gendered research' regarding shifting cultures of home, family and community. Again here, young people are involved as actors in their own lives, and the project follows Freire's advocacy of popular education as 
action, through raising awareness of issues and potential for communities/individuals to make change.

Key themes echo through these articles. Each narrative grapples with PAR's aim to resist oppressive structures and hegemonic discourses that socially and spatially marginalize, within the research process as in the wider world. Through reflexive analysis of projects, these articles are cognizant of and make visible issues of power, inequality, voice, agency and difference, highlighting the importance of developing research design and ethics together with participants, and the difficult and tension-filled negotiations constantly present in research. Messy and contested, attempting to address situated, myriad asymmetric power relations, PAR praxis aims to refuse binaries and normative constructions used to marginalise and oppress through patriarchal, colonial and capitalist systems, and adopt more horizontal focus on who steers and benefits through research: eg. participants asking questions of health ‘experts' outside diagnostic contexts (Rooke 2010). Threaded through this work are significant challenges around whose voices are present/heard/re-presented, and diverse geographies of power as limiting. This speaks to wider debates in PAR regarding epistemological and ontological interventions/orientations to social and spatial justice (Wynne-Jones et al. 2015). Given these themes, re-viewing PAR in GPC is more complicated than I first envisaged, since the text bolded in the previous paragraph aligns with feminist commitments more broadly. Celebrating 10 years of the Janice Monk lectures, Sally Marston and Sapana Doshi $(2016,1658)$ depict the analytic utility of gender, and core project of feminism, as 'foregrounding the political stakes and implications of theory for understanding and advancing social change'. Indeed, there are various versions of participation/participatory in feminism, raising questions as to how, why and where PAR is conceived/written/enacted as specific from 'feminist methodologies'. Some PAR praxis prioritises instead postcolonial, anti-racist and queer epistemologies, (here I recognise that there are complex and contested 
politics/positionings in which feminisms, anti-racisms, postcolonialisms and queer theories converge and diverge), and far from all feminist research adopts PAR commitments. Further unpacking how PAR and feminist work intersect, might engender deeper appreciation regarding what PAR can add to doing feminist geography.

\section{Collaborations}

Marston and Doshi themselves point to contemporary 'participatory research' as an evolving set of diverse feminist methodologies. They describe PAR as 'one of the ... participatory methods' (ibid.), epitomising feminist ethics through researcher-community partnerships with the goal of enabling change in research partners' lives. These partnerships are necessarily varied, and participatory research broad, because each project needs to respond to its particularities. They point to Gerry Pratt's lecture (2009) as one exemplar, in which partnerships with activist groups and Filipina live-in caregivers in Canada are critical. Testimonials are used in drama performance, producing an audience to witness caregivers' stories of family separation, and the violences of the Canadian temporary work visa program, to shift public opinion and challenge the policy and practice of state. Similarly collaborative, Caitlin Cahill's (2016) lecture explores a PAR project that sets out to scrutinise racialised policing in New York through everyday experiences of 'stop and frisk' of young men of color. Cahill's research foregrounds co/developing projects together with Researchers for Fair Policing to highlight the role of gentrification and securitisation, through public engagement of various kinds, to contest and change dominant constructions of criminal, racialised masculinity.

Marston and Doshi further discuss Richa Nagar's (2013) lecture as participatory research. Nagar's reflections on long term collaboration with activists in India outlines a feminist commitment to co-produced story-telling and co-authorship that questions/unsettles 
whose knowledge counts, and points to how dominant forms of academic engagement privilege (especially white, Western) academics. Such collaborations, working together with others, cross-cut PAR and feminist collaborative praxis: co-producing research design, questions, knowledges and outcomes, precisely as epistemological and ontological approaches. Crucially, this involves emphasising process as central to calling forth new ways of collecting data, of learning and encountering one another, of being in the world. There are, then, necessarily multiple understandings of what constitutes PAR and/or/as collaborative research. As Nagar problematizes any single/definitive project of 'feminism' (cited earlier), any understanding of PAR must simultaneously remain mobile and slippery, not dictate one privileged or 'correct' 'method', yet critically holding onto feminist politics offfor social and spatial justice.

On this point, Koni Benson and Richa Nagar $(2006,582)$ call for collaborative methodologies as resistance, as process that contests the ways in which neoliberal universities and donor-driven NGOs undercut feminist politics through redefining the ‘terminologies and terrains of women's politics, but also the sites and meanings of knowledge production'. Feminist oral histories and ethnography are suggested to counter dominant discourses around voice and memory, to forge other knowledges and actions. Such argument resonates with Jan Monk herself, whose collaborations with researchers from non-AngloAmerican countries subscribed to an agenda of collaboration as subversive (see Fenster 2007).

Similarly, working collaboratively with indigenous Mexican women in the US and Mexico, Elizabeth Sweet and Sara Ortiz Escalante $(2017,594)$ describe a project in which 'this process of data collection, self-awareness and action as inherently linked to the native concept territorio cuerpo-tierra, the landscape of bodies-lands'. Their article highlights how indigenous perspectives already undo binaries in western thinking between selves and land, 
public and private spaces, working instead towards community safety through process, which understands the continuity across collective spatial knowledges and individual bodily experiences of violence. Planners can thus be positioned alongside communities as co-actors, in collaborations to make spaces safer for women. Meanwhile, Eduarda Ferreira and Regina Salvador (2015) argue that collaboratively created web maps have the potential to disrupt heteronormativity in public spaces, opening them up as places of empowerment for lesbians and bisexual women. Working with women, these authors consider how virtual mapping of less exclusionary sites can provoke agency for public displays of same-sex affection, thus prompting social change.

Certainly, there is need to be attentive to how resistance and agency are recouped through normative power and discourse, and how diverse meanings and experiences of collaboration and participation unfold. Alison Mountz, Ines Miyares, Richard Wright and Adrian Bailey (2003), collaborating with transnational participants across USA and El Salvador, acknowledge that 'team members' (academic researchers) had different perspectives on what participatory research entailed. This article explores how a desire to support the Salvadorans' political struggles influenced fieldwork, as the project evolved to try to support participants' cause, yet intra-team politics also at times diminished engagement with participants. The authors problematise 'methodological becoming' as research collaborations develop in unforeseen and messy ways (also Houston et al. 2010).

Such issues resonate clearly across PAR and collaborative methodologies, and have long been called out by indigenous scholars and communities (Tuhiwai Smith 2012). A key challenge lies in not reiterating hierarchies embedded in colonial and patriarchal histories and geographies of academia; deeply ingrained exclusions and power relations entrenched in the structural oppression of neoliberal university systems, funding regimes, audit processes and so on. A critical concern here is not to 'name/claim' collaborative research/projects as PAR, 
and attend to rigorous critique of PAR that disregards critical race, queer and postcolonial theories (see also later). Rather my aim here is to frame connections between those radical feminist approaches that speak across a continuum of methodologies, underpinned by related ethics and commitments to justice.

In a GPC forum (Chowdhury et al. 2016) discussing Nagar's book Muddying the waters - coauthoring feminisms across scholarship and activism, authors discuss practices of knowledge making, situated solidarities, narrative, fieldwork and corporeality within, without and despite academia. Elora Halim Chowdhury (ibid., 1803) outlines the relational positions in collaborative projects as fraught, and the importance of not 'collaps[ing] the roles of the academic and the activist and to maintain a strategic and analytic distance between the two'. This prompts me to move onto the 'action' of PAR and /as feminist research.

\section{Actions}

As hopefully evident already, action through participations and collaborations are diverse. Foremost is that which focuses on critical pedagogy through self-education and awareness raising (after Freire), intending/enabling people to make changes in their own lives, and trying to effect changes in their local communities: building solidarities among communities of color in New York and trans-individuals in the UK, shifting cultural norms/social behaviours to improve health in Uganda and Botswana, addressing family gender roles in Vietnam and Ireland, making policy interventions with mothers of street youth in Bolivia, working with women and planners towards better design of safer spaces in Mexico. Importantly, PAR is not done to or action taken for participants; participants are active/key actors in addressing discursive and material inequalities.

However, there is research (that I've read elsewhere than GPC, and not cited here) that claims participation/participatory, in that people have participated in a project, without 
feminist ethics or commitment to social and spatial justice; without orientation to action, or critical attention to negotiating subjectivities, privileges and power in the research process. Further, there is serious risk in research (echoing widespread governmental and development contexts and practices) that recouped notions of participation-as-extraction in neoliberal agendas does real harm. In the UK, eg., the rise of 'impact' audit has seen much research claimed as having effects on, rather than working with, participants/publics (Pain 2014). Extractive research reiterates wider hierarchies and oppressions. In trying to forge more equitable social and spatial relations, the 'action' element is vital in PAR. (Likewise, there seems jeopardy in losing the 'participatory' aspect of PAR for the same reasons; research that does action despite the 'subjects' of its focus is anathema to feminist politics.)

Feminist work that acts with participants is critical to address issues of equality, whether narrated as explicitly PAR or not. For example, Ruth Evans $(2016,1360)$ draws on feminist ethnography that includes 'participatory workshops', spaces that foster counterdiscourses and 'micro-scale shifts in women's and men's positionings [to] reveal a recognition of the gender discriminatory nature of customary and Islamic laws and a desire to 'change with the times'. Similarly, Maria Hadjipavlou $(2006,329)$ positions herself as 'participant, observer or facilitator' in a series of inter-ethnic women's workshops, exploring the role of gender in peace processes in Cyprus. Conflict resolution skills emerged among the women, that the article argues challenge dominant state discourses and practices, opening up new spaces in which diverse perspectives and mutual trust can be built.

The action in Fernando Bosco, Stuart Aitken and Thomas Herman's (2011) work centres on the community participation of Latina immigrant mothers and children in neighbourhood advocacy near the US-Mexico border, aimed at improving healthcare, neighbourhood infrastructure and community ties. Through focus group data, the authors argue 'that these women and children have been successful in creating their own spaces for 
political participation' (156). This could initially read as 'traditional' research reporting on participants' actions; yet crucially the focus groups were only possible due to much longer term collaborations between researchers and community groups, out of which the project with mothers and children grew, and focus groups were used as opportunities for 'reflexive, participatory research practices' which fed into action.

These articles exemplify feminist commitment to action for progressive change, through careful engagement with people and place. In emphasising actions, resonances across PAR and certain feminist geography is clear. What also echoes across such work is that scholarly publications focus heavily on knowledge production, with 'action' mentioned in passing, in conclusion, inherently. This resonates with my own stories: academic articles/book chapters tell theory and 'key themes' emerging through research, while reports/toolkits/policy recommendations foreground action in non-academic fora/publications. This goes to normalised structures of academia, and is one of many enduring conundrums for PAR.

\section{Limitations}

Academics usually engage with limitations to their work. PAR, in its commitment and orientation to how scholars understand, mutually re-produce and act in the world, in line with feminist ethics, must attend to issues of power, privilege and subjectivity as central to any transformative process. I've endeavoured to problematize PAR throughout this re-view, precisely through the struggles and challenges set out by authors themselves. Further, Mcllwaine and Datta (2004) explicitly point to how PAR can be gendered, as wider structural norms re-imprint in PAR: with men talking over women in workshops, and women/more marginalised individuals taking on, and being asked to take on, greater burden in PAR projects. Normative discourses around community and care, and material realities already 
embedded in these discourses, can be central in women taking up additional roles as community co-researchers, since, already doing the bulk of home/child/family work, they are 'placed' as having time/space for co-research (ibid.). This is mirrored in universities. PAR and action-oriented feminist research takes significant time, effort and care, and adopting such praxis means undertaking less of those activities more valued/rewarded in the increasingly individualist, neoliberal academy (Askins and Blazek 2016).

Re-emergent debates around indigenous geographies and de-colonising the discipline are also pertinent here: as mentioned previously, much damage is done in name of 'collaboration' and 'participation' when recouped through patriarchal, colonial structures. The experiences of women of colour in the discipline remain caught up in its 'historical engagement with colonialism and imperialism [which] work to ensure the continued domination of whiteness among faculty and students within geography' (Mahtani 2006, 21). Nik Heynen (in Chowdhury et al. 2016, 1806) points out that his position as a white man must always be called out, for the potentially exploitative 'associated oppressive logics' within his various privileged positions, and that metropolitan academics must recognise their implication in forms of epistemic violence, and the requisite efforts required on their part to build and maintain trust and working relationships. Such efforts reverberate constantly through PAR.

Indeed, PAR scholars struggle with how analysis highlights researchers' views over participants', reiterating centre-periphery binaries and privileges. Kathryn Brickell (2015) addresses this explicitly, by writing the different analyses of research (by herself, and by local people) separately, and reflecting on these. Thus a plurality of voices are presented, situating herself, as white western academic, simultaneously through diverse readings of research themes among variously positioned participants. This strategy of narrating differences, rather than a story of consensus, is also evident in articles that discuss 'triangulation' of research 
findings, in which analysis is initially undertaken by academic researcher, but findings taken to participants for further discussion and development (eg. Waite and Conn 2011). Likewise, Browne et al. (2017) refuse comparability or categorisation of India or the UK in reductive ways, holding space open for diverse methods, analyses and actions.

Such attempts never claim an impossible 'best practice', rather continuously contending with situated inequalities. It is not enough to recognise difference and power: examining difference is not the same as resisting or addressing privilege around gender/race/age/sexuality/ability - within research teams, between researchers and participants, among differently positioned participants, between co/researchers and policy makers, practitioners and other academics. Persistently negotiating/addressing power inequalities is time-consuming, an issue mentioned in many articles cited here. 'Time' limits PAR in a range of ways (PyGyRG 2012), and its ghosting through GPC articles speaks to recent debates in feminist geography on the need for slower, more engaged scholarship (Mountz et al. 2015). PAR is also exhausting, exhilarating, embodied and emotional.

\section{Emotions}

'Not only is the telling of one's story crucial, but also the being heard' (Cahill 2007, 276). What scream out from PAR articles are the intimate, emotional and embodied relationships, responsibilities, challenges and achievements, that demand attention to more-than-rational ways of being and knowing; beyond the text, the page, the research proposal or final report. Carte and Torres $(2014,1268)$ write of 'those more subtle actions that usually pass as insignificant, and might not always be articulated verbally, are also expressed through gestures, body language or acts'. McIntyre $(2003,49)$ describes how 'together, we spent many hours talking, laughing, crying, eating, drinking tea'. Gabriela Valdivia (2009) explores how bodies and interpersonal interactions are central to construction of indigenous 
subjectivities in Ecuador, arguing that bodies and their 'grammar' are spaces in which indigeneity is reiterated and simultaneously contested. She highlights the potential of thinking with bodies, to deepen postcolonial understanding around indigeneity, through attention to intersectional corporeal differences mediated by race, sex and age. There are nuanced debates elsewhere regarding how emotions and embodiment are conceived; here I point to emotions and embodies geographies as central in PAR.

Working closely together with participants, negotiating fraught power relations and complex 'contact zones' (Torre and Fine 2008), demands openness to emotional, non-verbal, visceral elements of experiences, precisely through attention to process and ethics. Collaboration as resistance holds the potential of moving/becoming beyond rational and verbal selves and knowledges, to include other local capacities for raising awareness of injustices, and mobilising community support and action for change. Emotions not only emerge, but work through/across relational, embodied geographies. The articles re-viewed above commonly highlight the complex and ambivalent emotional geographies of such research. Participants' body-maps (Sweet and Escalante 2017) tell stories of sensory spatial experiences as sites of both pain and strength, brokenness and wholeness, of darkness and isolation and love and strength. Articles also speak to desire for justice as a clear motive through PAR work, often made visible as what Laura Pulido calls a 'corporeal politics of solidarity' (in Chowdhury et al. 2016, 1803). Indeed, Nagar's concept of 'radical vulnerability' echoes through much PAR work 'as a mode of enabling and deepening contextually grounded engagement with epistemic and ethical responsibility in relation to politically engaged alliance work' (ibid., 1800).

A strong theme is that emotional and embodied working is crucial in building trust; while gaining trust facilitates emotional and embodied research. While less explicitly unpacked, trust emerges as an emotional bond that requires constant labour (as all 
relationships do), and speaks to concerns around interdependence and reciprocity among all involved in PAR. Undertaking this re-view of PAR work in GPC, I'm re-minded that researchers require help from multiple others for projects to unfold, and there is a need to remain humble, thankful and consider carefully what academics are bringing to the process. These issues connect to wider feminist literatures on 'giving back' and 'being useful' (mrs.c.kinpaisby-hill 2011; Taylor 2014), and re-emergent debates regarding feminist ethics of care.

Further, the intimacy written through many PAR accounts speaks implicitly to feminist geopolitics, regarding interconnections of everyday, embodied and emotional geographies through diverse scales (Smith 2014). By highlighting relations of power acting upon and through bodies, PAR alerts us to the diversity of emotions, positions, attitudes and comportments that produce the geopolitical, which simultaneously enhance or constrain particular geopolitical subjectivities (see Dixon and Marston 2011; Smith 2011; and Heynen and Mahtani above). Such intimacies also resist analytic closure, which remains marginalised in normative academia; tentative suggestions over definitive conclusions, or mention of the emotional, are often dismissed. GPC offers a space for careful attempts to uncover and respond to (the role of) emotions, without making totalising claims or meta-theory, as feminist praxis. Indeed, my experience is of PAR as emotionally interlaced through wider geographies, knitted through teaching, administrative, mentoring, reviewing and other collegiate duties. That is, PAR, as epistemological commitment and ontological orientation to producing more 'just' societies and spaces, opens up/demands thinking-feeling our way forwards in-and-beyond academia (Askins and Blazek 2016).

\section{Continuations}

Once upon a time, I questioned what I was doing in 'the academy'. Through this re-view, 
I've queried how, why and where PAR is conceived/written/enacted as (specific from) feminist geography. In Gibson-Graham's (1994) words: ‘stuffed if I know!' Because I've relearnt through writing this story that PAR cannot be 'known' as a unified approach, or neatly defined research methodology, precisely in its situatedness and interdependencies. PAR centres around voices and narratives such that myriad knowledges can be brought forth; listening, learning, acting with others towards social and spatial justices. Heedful of complex politics, discursive shifts and material conditions, such work is always unfolding and in process. GPC encourages diverse, wide-ranging work, committed to publishing materials that 'open the boundaries of feminism' (Bondi, Staeheli and Valentine 1999): PAR research clearly makes a significant contribution, with challenges and opportunities ahead.

As already mentioned, feminism and PAR have more to learn from critical race and queer theories, as other epistemological and politicised projects that set out to enact progressive change. While some work re-viewed here draws on such analyses (eg. Cahill 2007; Browne et al. 2017), these are less explicitly explored in writing, though my sense/experience is they are likely more central in praxis. In the current political era/crisis of xenophobic, ultra-capitalism, interventions that progress PAR with/through critical race and queer perspectives are surely vital.

Meanwhile, recent turns to the anthropocene, assemblage and more-than-human geographies prompt re-engagement with the actor network theory of my $\mathrm{PhD}$ studies, and I'm re-minded of urgencies of environmental issues. The critical challenge here is to take animals, plants, rivers, minerals, country seriously, as active co-producers of knowledge, without reducing (them) as knowable subjects (see Gibson-Graham 2011). PAR arguably has capacities to co-develop research design and ethics with those who do not communicate verbally: and, rather than be seduced by 'agenda-pushing theory', PAR and collaborative feminist work must be wary of appropriating ontologies and epistemologies long integral to 
non-Western/global south/indigenous communities ('posthumanism' as a colonial move). Instead, developing environmental work through embodied, emotional and action-oriented approaches, including the critical need to re-think and act differently the carbon footprints/environmental impacts of doing research, including its dissemination. For example, it has always struck me that flying around the world (for research meetings, to deliver papers, etc.) risks undermining feminist tenets, especially given how climate change adversely affects communities of colour.

I pointed earlier to a lack of explicit writing up of actions in academic fora. Scholarship/GPC can look to open up publishing that foregrounds such aspects, which may necessitate letting go of 'traditional' article structures, lengthy theoretical framings, etc. Simultaneously, writing itself remains a key action in all of this: co-authoring is critical to representing testimonies/tales in ways that undermine normative, masculinist, neoliberal edifices; stories as rigorous and robust. Articles cited through this re-view are testament to academic writing as necessarily collaborative, yet-still rarely are co-researchers named on academic articles, or involved in writing projects, even in GPC. As the journal adopts themes of 'feminist ethos of care' and 'mentoring' to celebrate its 25 years of publication, let us intensify emphasis on interdependence and care ethics in how and what we do-and-write, think-and-feel, to further foreground diverse voices and work towards justice. Let us be part of making progressive changes, co-produced with people and place, with a view to what stories future scholars may tell in 25 years' time.

\section{Acknowledgements}

Heartfelt gratitude goes to all authors cited here, and multiple others, who have inspired and enriched my academic journey through PAR. Across many pages, and in person, I've been so fortunate to learn from and with co-researchers, participants, colleagues and students. My thanks also to the anonymous reviewers for their generous and supportive reading and reflections on the first draft, which significantly helped hone this review. I used to acknowledge 'all omissions and errors as my own' - I 
now lean more towards conceiving of such omissions/errors as less a 'failing', rather as opportunities to further open up debate $:$.

\section{Notes on contributor}

I am a human geographer with research interests focusing on identity, belonging, citizenship, emotions and everyday geographies of resistance and agency. My approach is actively engaged research that, theoretically and methodologically, challenges dominant discourses and emphasises participants as co-producers of knowledge. Current research explores how mundane geographies dis/enable 'meaningful' encounters between long term residents and newcomers to inner city areas.

\section{References}

Askins, Kye and Matej Blazek. 2016. "Feeling our way: academia, emotions and a politics of care.” Social and Cultural Geography 18(8): 1086-1105.

Benson, Koni, and Richa Nagar. 2006. "Collaboration as Resistance? Reconsidering the processes, products, and possibilities of feminist oral history and ethnography." Gender, Place and Culture 13(5): 581-592.

Berckmans, Isabel, Marcela Losantos Velasco, and Gerrit Loots. 2016. "Breaking silence: exploring motherhood and social transformation in a participatory action research with Alteñan mothers." Gender, Place and Culture 23(7): 1017-1032.

Bondi, Liz, Lynn Staeheli, and Gill Valentine. 1999. "Editors' Introduction.” Gender, Place and Culture 6(4): 309-310.

Bosco, Fernando.J., Stuart C. Aitken, and Thomas Herman. 2011. "Women and children in a neighborhood advocacy group: engaging community and refashioning citizenship at the United States-Mexico border." Gender, Place and Culture 18(2): 155-178.

Brickell, Katherine. 2015. "Participatory video drama research in transitional Vietnam: postproduction narratives on marriage, parenting and social evils." Gender, Place and Culture 22(4): 510-525.

Browne, Kath, and Jason Lim. 2010. "Trans lives in the "gay capital of the UK." Gender, Place and Culture 17(5): 615-633.

Browne, Kath, Niharika Banerjea, Nick McGlynn, B. Sumita, Leela Bakshi, Rukmini Banerjee, and Ranjita Biswas. 2017. "Towards transnational feminist queer methodologies." Gender, Place and Culture 24(10): 1376-1397.

Cahill, Caitlin. 2007. "The Personal is Political: Developing new subjectivities through participatory action research." Gender, Place and Culture 14(3): 267-292. 
Carte, Lindsey, and Rebecca M. Torres. 2014. "Role playing: a feminist-geopolitical analysis of the everyday workings of the Mexican state." Gender, Place and Culture 21(10): $1267-1284$.

Chowdhury, Elora Halim, Laura Pulido, Nik Heynen, Lainie Rini, Joe Wainwright, Naeem Inayatullah, and Richa Nagar. 2016. "Muddying the waters: co-authoring feminisms across scholarship and activism - Book Review Forum." Gender, Place and Culture 23(12): 1800-1812.

Cook et al. 2014. "Organic Public Geographies and REF Impact.” ACME: International eJournal for Critical Geographies 13(1): 47-51.

Dixon, Deborah .P, and Sallie A. Marston. 2011. "Introduction: feminist engagements with geopolitics." Gender, Place and Culture 18(4): 445-453.

Evans, Ruth. 2016. “Gendered struggles over land: shifting inheritance practices among the Serer in rural Senegal." Gender, Place and Culture 23(9): 1360-1375.

Ferreira, Eduarda, and Regina Salvador. 2014. "Lesbian collaborative web mapping: disrupting heteronormativity in Portugal." Gender, Place and Culture 22(7): 954-970.

Freire, Paulo. 1997[1970]. Pedagogy of the Oppressed. Middlesex: Penguin Books.

Gibson-Graham, J.K. 1994. "'Stuffed if I know!': Reflections on post-modern feminist social research." Gender, Place and Culture 1(2): 205-224.

Gibson-Graham, J.K. 2011. "A feminist project of belonging for the Anthropocene.” Gender, Place and Culture 18(1): 1-21.

Giritli-Nygren, Katarina, and Ulrika Schmauch. 2012. "Picturing inclusive places in segregated spaces: a participatory photo project conducted by migrant women in Sweden." Gender, Place and Culture 19(5): 600-614.

Hadjipavlou, Maria. 2006. "No Permission to Cross: Cypriot women's dialogue across the divide." Gender, Place and Culture 13(4): 329-351.

Houston, Serin D., D. James McLean, Jennifer Hyndman, and Arif Jamal. 2010. "Still methodologically becoming: collaboration, feminist politics and 'Team Ismaili'." Gender, Place and Culture 17(1): 61-79.

Johnson, Louise C. 2008. "Re-placing gender? Reflections on 15 years of Gender, Place and Culture." Gender, Place and Culture 15(6): 561-574.

Mahtani, Minelle. 2006. "Challenging the Ivory Tower: Proposing anti-racist geographies within the academy." Gender, Place and Culture 13(1): 21-25.

Marston, Sallie A., and Sapana Doshi. 2016. "The Janice Monk Lecture in Feminist Geography: the first 10 years." Gender, Place and Culture 23(12): 1657-1664. 
McIlwaine, Cathy, and Kavita Datta. 2004. "Endangered Youth? Youth, gender and sexualities in urban Botswana." Gender, Place and Culture 11(4): 483-512.

McIntyre, Alice. 2003. "Through the Eyes of Women: Photovoice and participatory research as tools for reimagining place." Gender, Place and Culture 10(1): 47-66.

Mountz, Alison, Ines M. Miyares, Richard Wright, and Adrian J. Bailey. 2010.

"Methodologically Becoming: Power, knowledge and team research." Gender, Place and Culture 10(1): 29-46.

Mountz, Alison, Ann Bonds, Becky Mansfield, Jenna Loyd, Jennifer Hyndman, Margaret Walton-Roberts, Ranu Basu, Risa Whitson, Roberta Hawkins, Trina Hamilton, and Winifred Curran. 2015. "For slow scholarship: A feminist politics of resistance through collective action in the neoliberal university." ACME: An International EJournal for Critical Geographies 14(4): 1235-1259.

mrs.c.kinpaisby-hill 2011. "Participatory Praxis and Social Justice.”" In Del Casino Jr., V. J., Thomas, M., Cloke, P. and Panelli, R. (eds.) A Companion to Social Geography. Wiley-Blackwell: 214-234.

Pain, Rachel. 2014. "Impact: Striking a blow or walking together?” ACME: An International E-Journal for Critical Geographies 13(1): 19-23.

PyGyRG 2012. “Connectivity, Creativity, Hope, and Fuller Subjectivities: a Communifesto for Fuller Geographies.” Available at https://radicalantipode.files.wordpress.com/2012/12/pygyrg-reply.pdf

Rooke, Alison. 2010. "Trans youth, science and art: creating (trans) gendered space." Gender, Place and Culture 17(5): 655-672.

Smith, Sara. 2011. "'She says herself, "I have no future": love, fate and territory in Leh District, India." Gender, Place and Culture 18(4): 455-476.

Smith, Sara. 2014. "Intimacy and angst in the field." Gender, Place and Culture 23(1): 134146.

Sweet, Elizabeth L., and Sara Ortiz Escalante. 2017. "Engaging territorio cuerpo-tierra through body and community mapping: a methodology for making communities safer." Gender, Place and Culture 24(4): 594-606.

Taylor, Myfanwy. 2014. "Being useful' after the Ivory Tower: combining research and activism with the Brixton Pound." Area 46: 305-312.

Tuhiwai Smith, Linda. 2012. Decolonizing Methodologies: Research and Indigenous Peoples. London: Zed Books. 
Valdivia, Gabriela. 2009. "Indigenous bodies, indigenous minds? Towards and understanding of indigeneity in the Ecuadorian Amazon." Gender, Place and Culture 16(5): 535551.

Waite, Louise, and Cath Conn. 2011. "Creating a space for young women's voices: using 'participatory video drama' in Uganda." Gender, Place and Culture 18(1): 115-135.

Wynne-Jones, Sophie, Peter North, and Paul Routledge, P. 2015. "Practising participatory geographies: potentials, problems and politics." Area 47(3): 218-222. 